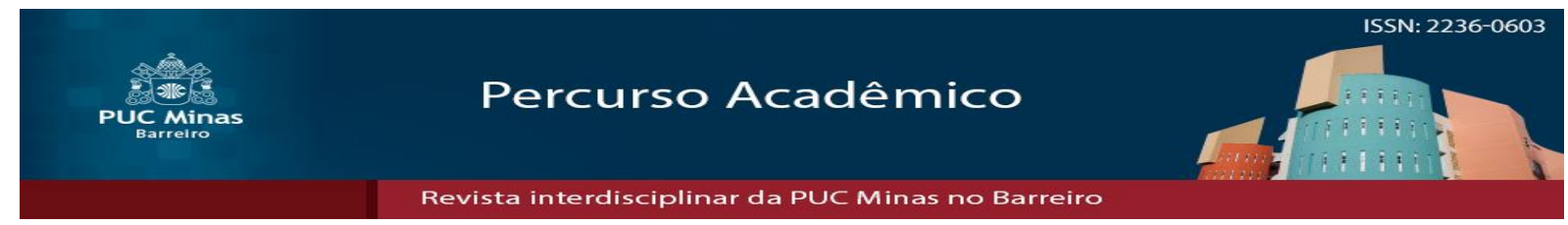

\title{
A Literatura como fonte emancipatória curricular na busca da efetivação da educação como Direito Fundamental
}

\section{The Literature as a curricular emancipatory source in search of the effectiveness of education as Fundamental Law}

\author{
Nayane Costa Nascimento ${ }^{1}$ \\ Alexandra Carolina Botelho ${ }^{2}$
}

\begin{abstract}
Resumo
O presente artigo possui como escopo a abordagem do incentivo à literatura na base educacional como um direito fundamental, isto é desde a educação infantil ao ensino médio, na medida em que a educação consiste em garantia prevista no artigo 205 da CR/88: "a educação, direito de todos e dever do Estado e da família, será promovida e incentivada com a colaboração da sociedade, visando ao pleno desenvolvimento da pessoa, seu preparo para o exercício da cidadania e sua qualificação para o trabalho"; portanto, sua natureza fundamental está interligada ao próprio desenvolvimento da personalidade dos cidadãos, sendo, inerente ao princípio da Dignidade da Pessoa Humana. Nesse prisma, o que se defende aqui consiste na premissa de que a Literatura representa verdadeira fonte emancipatória curricular, uma vez que o seu estudo possibilita aos alunos uma nova forma de construção própria do conhecimento, de modo a evitar que se criem barreiras para "o pensar", repelindo o instrucionismo que nega horizontes e que limita o aprendizado aquilo que lhe é imposto.
\end{abstract}

Palavras-chave: literatura; educação; direito; conhecimento, cidadania.

\begin{abstract}
This article has as its scope the approach to encouraging literature in the educational base as a fundamental right, that is, from kindergarten through high school, since education is a guarantee provided for in article 205 of CR / 88: "the education, the right of all and the duty of the State and the family, will be promoted and encouraged with the collaboration of society, aiming at the full development of the person, his preparation for the exercise of citizenship and his qualification for work ", therefore, is linked
\end{abstract}

Artigo recebido em 09 de Agosto de 2018 e aprovado em 06 de Fevereiro de 2019

1 Mestranda em Educação pela Pontifícia Universidade Católica de Minas Gerais (Puc-Minas). Especialista em Direito Civil e Processo Civil pela UNICOC. Especialista em Direito do Trabalho e Processo do Trabalho pela UNICOC e especialista em Ciências Criminais pela Universidade Cândido Mendes- UCAM. Advogada e Professora de Direito da Pontifícia Universidade Católica de Minas Gerais (Puc-Minas). Brasil. E-mail: nayanecn@yahoo.com.br

${ }^{2}$ Advogada, graduada pela Pontifícia Universidade Católica de Minas Gerais. Participante do grupo de estudos Precedentes e Ética Constitucional (PEC) da Pontifícia Universidade Católica de Minas Gerais (PUC Minas), registrado pelo CNPQ. Brasil. E-mail: alexandracarolinabotelho@gmail.com 
to the very development of the personality of the citizens, being inherent to the principle of the Dignity of the Human Person. In this perspective, what is defended here consists in the premise that Literature represents a true emancipatory curricular source, since its study allows the a new way of building knowledge itself, so as to avoid creating barriers to "thinking", repel the instructionalism that denies horizons and limits learning to what is imposed on it.

Keywords: literature; education; right; knowledge, citizenship.

\section{Introdução}

O presente escrito abordará a extrema relevância da Literatura na grade curricular da educação básica, representando verdadeira fonte emancipatória, tendo como resultado a efetivação da educação como um Direito Fundamental.

Em primeiro momento será realizada uma breve análise histórica do transcurso da Educação no Brasil, entre elas, Lei de Diretrizes e Bases da Educação Nacional - Lei 9.394/96, que teve como objetivo principal traçar um padrão equitativo de forma a garantir certa coerência no sistema educacional das regiões do país.

Em que pese às "boas intenções" da referida lei, no sentido de estabelecer um modelo curricular "igualitário", há de se questionar formas de ensino em que se observa um engessamento das áreas de estudo de modo a impossibilitar ao aluno a autonomia da pesquisa e construção de seu conhecimento, o que teria um resultado antagônico ao aprendizado.

Nesse sentido, será apresentada uma discussão doutrinária sobre a forma em que a literatura é abordada em sala de aula no âmbito das escolas de educação básica, o que, por vezes não se prioriza a qualidade da obra literária em si, bem como a imersão da realidade social e leitura crítica, o que ocasiona resultados alarmantes que são reiteradamente constatados pelos professores universitários. Além do mais, será abordada a literatura como um Direito Fundamental, utilizando-se como bibliografia base o livro "Saber Pensar" de Pedro Demo, bem como "Quarto de despejo" de Carolina Maria de Jesus.

Nesse prisma, o referido artigo visa apontar a importância da Literatura, na medida em que possibilita a efetivação de uma educação minimamente digna, bem como sua repercussão no âmbito social e o impacto no sistema educacional como Direito Fundamental. 


\section{Breve análise histórica do transcurso da Educação no Brasil.}

Como forma de complementar e traçar embasamentos sólidos ao presente escrito apresenta-se uma breve análise histórica acerca do transcurso da educação no Brasil, de modo a discorrer sobre a chegada da Escola Nova, bem como sobre a elaboração e aprovação da primeira Lei de Diretrizes e Bases da Educação Nacional (LDB 4.024/61).

Em meados da década de 40, sob forte influência da hegemonia americana chega-se ao Brasil a pedagogia da Escola Nova, suplantando uma pureza científica e o fechamento do mundo acadêmico, no seu ciclo de "standartização" reprodutora do conhecimento, gerando uma esfera de proteção e isolamento do educando com a realidade.

Em 1961, já sob o Controle do Conselho Federal de Educação, surgia o "Currículo Mínimo", nesses termos preleciona o artigo 210 Constituição Federal "serão fixados conteúdos mínimos para o ensino fundamental, de maneira a assegurar formação básica comum e respeito aos valores culturais e artísticos, nacionais e regionais". (BRASIL, 2018).

A elaboração e a aprovação da primeira Lei de Diretrizes e Bases da Educação Nacional (LDB 4.024/61) ocorreram em meio a uma ampla discussão teórica sobre as mudanças necessárias para que a educação brasileira se modernizasse. Buscava-se, segundo o Conselho, com a substituição do currículo único pelo mínimo, mais liberdade para as escolas elaborarem os seus currículos, e, consequentemente, dos seus educandos às necessidades sociais. No entanto, as prescrições referentes ao currículo escolar apareceram de forma pouco elaborada no texto legal, impedindo que a oportunidade de haver uma ampla renovação educacional se consumasse. (MARCHELLI, 2014, p.1480).

Destaque para as silenciosas leis 5.540/68 e a 5.692/71 que derrogaram a lei $4.024 / 61$, no que tange ao ensino universitário e ensino de $1^{\circ}$ e $2^{\circ}$ grau, vigorando como objetivos a formação da criança e do pré-adolescente, a autorrealização do educando, a qualificação para o trabalho e o preparo para o exercício consciente da cidadania. (SAVIANI, 1980, p.135) 
Com o advento da Lei de Diretrizes e Bases da Educação. (Lei 9.394/96), foi permitida a criação de um sistema de avaliação do ensino sob o encargo do Estado. A Base Curricular Comum Nacional estava prevista tanto no artigo 201 da Constituição Federal, quanto no artigo 26 da LDB, que diz que "os currículos da educação infantil, do ensino fundamental e do ensino médio devem ter base nacional comum, a ser complementada, em cada sistema de ensino e em cada estabelecimento escolar".

Já aos auspícios da Lei de Diretrizes e Bases da Educação, de 1996, à União cabe a responsabilidade de "estabelecer, em colaboração com os Estados, Distrito Federal e os municípios, competências e diretrizes para a educação infantil, o ensino fundamental e o ensino médio, que nortearão os currículos e os seus conteúdos mínimos, de modo a assegurar a formação básica comum". Neste panorama, em 1997, o governo federal criou os parâmetros curriculares nacionais, a fim de orientar as escolas quantos aos conteúdos e habilidades a serem ensinados, uma referência para a elaboração dos currículos das unidades educacionais.

Em 2011, foram aprovadas as Diretrizes Curriculares Nacionais, dessa vez de implantação obrigatória. Tal documento engloba os princípios, fundamentos e procedimentos que devem orientar as práticas em toda educação básica.

Neste cenário, a lei de diretrizes e bases promulgada no ano de 1996, com nova

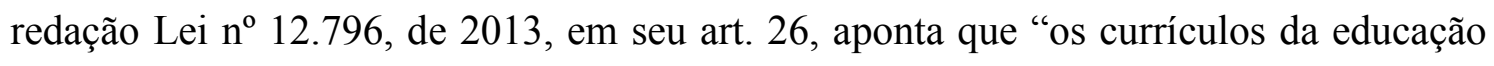
infantil, do ensino fundamental e do ensino médio devem ter base nacional comum, a ser complementada, em cada sistema de ensino e em cada estabelecimento escolar, por uma parte diversificada, exigida pelas características regionais e locais da sociedade, da cultura, da economia e dos educandos".

Conforme se verifica, a imposição governamental da implementação de uma educação engessadora, visa assegurar que todo educando, em todas as regiões do país, tenha garantido o acesso à aprendizagem de conhecimentos fundamentais, promovendo equidade e maior coerência em todo o sistema educacional, com texto uniformizador curricular nacional, conforme determinado no Plano Nacional de Educação. Ocorre, porém, que se faz necessário a criticidade capaz de garantir o acesso a aprendizagem que não cause o ocultamento do saber, no qual o resgate a literatura pode aproximar o 
sujeito educando a sua realidade de vida e consequentemente a promoção do direito a educação, o que será abordado mais a fundo em tópico posterior.

\section{O papel da literatura na construção do conhecimento: fonte emancipatória curricular}

Nos termos do que fora abordado em tópico anterior, a Lei de Diretrizes e Bases da educação nacional visou traçar um padrão equitativo de forma a garantir certa coerência no sistema educacional das regiões do país. Entretanto, há de se repelir formas de ensino em que engessam as áreas de estudo de modo a impossibilitar ao aluno a autonomia da pesquisa e construção de seu conhecimento, o que teria um resultado antagônico ao aprendizado.

O que se procura indagar no presente estudo consiste na abordagem do papel da Literatura na educação básica e como ela pode ajudar o educando na construção de seu conhecimento e, além disso, sob um aspecto cultural, poder se enxergar na sociedade em que vive e nela intervir, desenvolvendo-se a alteridade, na medida em que faço uma leitura do outro e me enxergo no outro, consigo compreendê-lo e lido com as diferenças de maneira a aceitá-las, entendendo-as como parte de uma história, de um contexto social.

Para Ivanda Maria Martins Silva (2003), não se se faz visível a sintonia entre os dois discursos "o da escola sobre a leitura e o da leitura sobre a escola", uma vez que, em que pese haverem conexões sob o aspecto de discursos teóricos, a falta de conectividade se observa diante de "um descompasso entre as práticas de leitura que circulam na escola e as discussões sobre leitura recorrentes fora do espaço escolar" (...) essas discussões teóricas geralmente perdem-se na prática de sala de aula, havendo mais "desencontros" que "encontros"” (...). (SILVA, 2003, p. 514).

Nesse prisma, Silva (2003) aborda três principais motivos pelos quais a "leitura, literatura e teoria literária deveriam estar estreitamente relacionadas no meio escolar", o primeiro motivo seria a própria interdisciplinaridade da leitura, sendo que no que se refere à leitura literária o ato de ler é influenciado por "estratégias cognitivas, lingüísticas, metalingüísticas, conhecimento do policódigo literário, noção de gênero 
literário, estilo de época no qual o texto está inserido, enfim, um conjunto de noções determinantes na interação do leitor com o texto”. (SILVA, 2003, p. 514).

Já o segundo motivo seria "a significação do texto literário ser construída a partir da participação efetiva do receptor, o que torna evidente as relações dinâmicas entre a literatura e o leitor", e, por fim, o terceiro motivo elucidado pela autora consiste no fato de que a teoria literária "só existe em função da leitura e da literatura", sendo tal característica extremamente relevante quando um texto literário é trabalhado em sala de aula. "A teoria literária deve estar presente na escola, subsidiando a prática do professor, no sentido de ampliar concepções críticas sobre o fazer literário e a recriação do texto pelo leitor, o que só ocorre no ato da leitura". (SILVA, 2003, p. $515)$.

$\mathrm{Na}$ esteira do abordado inicialmente, faz-se imprescindível salientar a significação da Literatura na formação humana, histórica e de consciência social do aluno, ponto esse que, além de sua relevância há de se questionar sua aplicabilidade em sala de aula.

Para Silva (2003), a referida prática de análise da literatura nem sempre são realizadas da forma como deveria ser em sala de aula, mas, ao contrário, o que costuma se observar consiste em prática antagônica ao verdadeiro objetivo da literatura, que seria o de "formar leitores críticos e autônomos capazes de desenvolver uma leitura crítica do mundo”. (SILVA, 2003, p. 515).

Contudo, na prática, essa noção ainda parece perder-se diante de outras concepções de leitura que ainda orientam as práticas escolares. Na escola, a leitura é praticada tendo em vista o consumo rápido de textos, ao passo que a troca de experiências, as discussões sobre os textos, a valorização das interpretações dos alunos tornam-se atividades relegadas a segundo plano. A quantidade de textos "lidos" (será que de fato são "lidos" pelos alunos?) é supervalorizada em detrimento da seleção qualitativa do material a ser trabalhado com os alunos. (SILVA, 2003, p. 515).

Nesse diapasão, Leyla Perrone (2006) aborda em seu artigo "Literatura para todos", considerações sobre a crise da Literatura como disciplina escolar e universitária, tendo como um de seus principais eixos a leitura crítica de documentos do MEC, que versam sobre tal assunto. Observa-se que no mesmo sentido abordado por Silva, Perrone tece relevantes observações de como a Literatura se faz necessária na formação do aluno, de forma a possibilitá-lo adentrar a Universidade de maneira mais saudável, na medida em 
que o básico, que seria o desenvolvimento da prática da leitura crítica, já seria previamente trabalhado. (PERRONE, 2006, p. 16).

Perrone (2006) faz um alerta em seu escrito, no sentido de que a Literatura como uma disciplina escolar e Universitária, "parece ameaçada a desaparecer". Aduz que no Brasil têm sido reiteradas as reclamações dos professores nas universidades, principalmente no curso de Letras e Ciências Humanas de que os alunos não apresentam gosto pela leitura, áreas essas em que a linguagem constitui "ferramenta indispensável para o conhecimento". (PERRONE, 2006, p. 17-18).

Para Perrone (2006), o cerne do problema pode ser apontado na educação básica, tendo em vista que é nesse momento que deveriam ser trabalhadas nos alunos competências mínimas para desenvolvimento da leitura e escrita, "o estado calamitoso de nosso ensino básico e secundário é de conhecimento geral, e tristemente comprovado pelos resultados dos estudantes brasileiros em provas de âmbito nacional e internacional". (PERRONE, 2006, p.18).

\begin{abstract}
As humanidades são o lugar onde a sociedade critica a si mesma, onde se estimula o senso critico dos alunos etc. Mas a atitude crítica, salutarmente mantida e incentivada, sobretudo num país que conheceu, em passado recente, vinte anos de regime autoritário, permanece solitária e quase inócua se ela não for acompanhada de propostas concretas para alterar um estado de coisas criticável. Da Universidade, esperam-se críticas, mas também propostas. E é nesse ponto que verificamos certo comodismo, e até mesmo certa arrogância na conduta dos professores universitários, entre os quais me incluo. Os alunos nos chegam cada vez mais ignorantes, isso é lamentável, mas não podemos fazer nada a esse respeito - é o que geralmente se ouve dizer. (PERRONE, 2006, p.19).
\end{abstract}

Nesse sentido, Perrone (2006) sugere que um passo para se faça algo em prol da mudança dessa realidade, seria uma atitude dos docentes universitários no sentido de se interessar pelo que ocorre no âmbito oficial, que por sua vez regula o ensino. Indagando, a título de exemplo, o fato de que entre 2001 e 2002, observou-se que a disciplina Literatura não mais constava inúmeros Estados do Brasil, e que "o ensino da literatura foi substituído por ou diluído sob a fórmula "comunicação e expressão", relata ainda que o "sumiço da literatura provocou alguns protestos isolados. Mas não aconteceu nenhum movimento geral de repúdio a esse 'desaparecimento'”. (PERRONE, 2006, p. 17-18). 


\section{Literatura como um Direito Fundamental}

Pedro Demo aponta que para que o ideário da educação seja alcançado, isto é, para "saber pensar" não basta só pensar, "é também, e sobretudo, saber intervir. Teoria e pratica, e vice-versa. Quem sabe pensar, entretanto, não faz por fazer mas sabe por que e como faz". (DEMO, 2000, p.17).

Desse modo, para que se cumpra a perspectiva da construção do "saber pensar" se faz necessário indagar a importância da literatura de forma a efetivar a garantia de uma educação minimamente digna, bem como sua repercussão no âmbito social, logo, o que se questiona é: Qual o impacto da literatura no sistema educacional? A literatura é um Direito Fundamental?

Tanto quanto um direito, a educação é definida, em nosso ordenamento jurídico, como dever: direito do cidadão - dever do Estado. Do direito nascem prerrogativas próprias das pessoas em virtude das quais elas passam a gozar de algo que lhes pertence como tal. Do dever nascem obrigações que devem ser respeitadas tanto da parte de quem tem a responsabilidade de efetivar o direito como o Estado e seus representantes, quanto da parte de outros sujeitos implicados nessas obrigações. Se a vida em sociedade se torna impossível sem o direito, se o direito implica em um titular do mesmo, há, ao mesmo tempo, um objeto do direito que deve ser protegido inclusive por meio da lei. (CURY, 2002).

A Educação em um sentido amplo se diz do meio de transferir valores, costumes, hábitos e informações para uma pessoa, ou grupo social. Após as concepções iluministas a educação passa a ser a condição do desenvolvimento do homem e do cidadão, sendo o marco de acesso às apreensões e apropriação dos conteúdos pelas pessoas na sociedade. É o campo essencial para o desenvolvimento da ciência comunicativa, uma vez que os processos educativos se dão pela via dos processos comunicacionais que se fazem a partir das interações realizadas pelos indivíduos dentro deste processo.

No sentido formal, a educação se mostra no processo de ensino e aprendizagem que busca desenvolver fisicamente o indivíduo e prepará-lo intelectualmente e moralmente para integrar-se a uma sociedade.

$\mathrm{Na}$ atualidade, são inúmeros os problemas sociais, a desigualdade, a desatenção para com as garantias fundamentais, isso também se visualiza no âmbito educacional, logo, o que se busca na presente pesquisa é questionar qual o significado da literatura 
para as crianças que acabaram de iniciar sua jornada estudantil? $\mathrm{O}$ que representa a literatura na base curricular de ensino? Do mesmo modo, qual o significado da literatura para o jovem, para o adulto que resolveu retomar os estudos, trabalhador, hipossuficiente, advindo de uma classe menos favorecida consubstanciada nas dificuldades materiais?

\begin{abstract}
A educação escolar é um bem público de caráter próprio por implicar a cidadania e seu exercício consciente, por qualificar para o mundo do trabalho, por ser gratuita e obrigatória no ensino fundamental, por ser gratuita e progressivamente obrigatória no ensino médio, por ser também dever do Estado na educação infantil. Esse bem público, capaz de ser como serviço público, aberto, sob condições, à iniciativa privada, é, no âmbito público cercado de proteção como, por exemplo, a Lei de Diretrizes e Bases da Educação Nacional, o Plano Nacional de Educação e os pareceres e resoluções dos Conselhos de Educação. Veja-se, por exemplo, a vinculação percentual de impostos na Constituição, a obrigatoriedade do censo escolar e a avaliação de desempenho escolar. (CURY, 2002).
\end{abstract}

Os currículos impostos no Brasil foram influenciados pelos resquícios do positivismo ao assumirem uma postura introspectiva, sustentada no modelo autoritário. Optando as escolas por uma postura acadêmica tradicional, fechada em si mesma, dedicada à erudição gratuita e desinteressada pela realidade nacional. Na realidade, as diretrizes curriculares impostas não acompanharam o momento histórico de cada época, vivendo um verdadeiro "museu de princípios e praxes", em que muitas vezes não há espaços para a literatura e o "saber emancipado".

O museu de praxes também se torna evidente ao apontarmos que tais currículos estudam a linguagem oficial do Estado. Este foi o problema central da nossa história curricular: transmitir e reproduzir o conhecimento oficial.

O currículo- reprodutor, como fruto de uma sociedade ideal, mas não real, não apresenta uma preocupação em saber se o educando está apto a responder a demanda proposta pela sociedade, ou simplesmente se há uma preocupação com o objeto cognoscível. A simples implementação de uma Base Nacional Comum da Educação, representa um fato social coercitivo, ou seja, exerce pressão social do saber manipulado sobre o indivíduo.

Nesta seara, podemos concluir que a falseabilidade de uma sociedade coesa, em total sintonia com os princípios funcionalistas da sobreposição da consciência coletiva 
em face da consciência individual, da internalização dos valores sociais, baseada na ordem e progresso como prevê Durkheim, nos leva ao ideal de um currículo comum a nível nacional como forma de enquadramento oculto do saber.

Adota-se no exposto escrito, como hipótese de pesquisa inicial, a concepção de importantes autores, que serão elucidados em momento oportuno, no sentido de que a literatura reflete uma significação para a educação, sendo que, em cada faixa etária, bem como em cada tempo, ela produzirá inúmeros efeitos positivos, não só para o crescimento do cidadão individualmente, mas, para a sociedade como um todo, tendo como resultado a narrativa, o enfrentamento, o combate das mazelas sociais, ainda que sob a perspectiva material, ora, em tempos de fome, ainda que na miséria, o "excluído", "os invisíveis"; através da literatura podem aprender e expressar seus conhecimentos do mundo.

\begin{abstract}
A gestão democrática como princípio da educação nacional, presença obrigatória em instituições escolares públicas, é a forma dialogal, participativa com que a comunidade educacional se capacita para levar a termo, um projeto pedagógico de qualidade e da qual nasçam "cidadãos ativos" participantes da sociedade como profissionais compromissados. (CURY, 2002).
\end{abstract}

Faz-se imprescindível a abordagem não só do papel da literatura como projeto pedagógico para crianças e jovens que cursam, normalmente, o ensino fundamental e médio, mas, também a transformação causada por ela na vida daqueles que, em decorrência de tantas exclusões em que a sociedade lhes submeteu, não tiveram a oportunidade de acesso à leitura.

Nessa seara, ensinar não significa simplesmente reproduzir os dogmas. O ensino com essas características é velho, comprometido com a ideologia das classes dominantes e, sobretudo, tem por objetivo naturalizar as injustiças. Segundo Rodrigues (1995), “a concepção do ensino vigente, que é a da educação tradicional, tem fortes vínculos com o positivismo e sua concepção de ciência e verdade" (RODRIGUES, 1995, p.16).

Percebe-se que, seja no Império, seja na República, a educação brasileira, historicamente, sempre se caracterizou por uma predominância da desigualdade com relação à igualdade. Os currículos preocupam com o estudo da linguagem oficial das classes dominantes e este foi o problema central da nossa história curricular: transmitir e 
reproduzir o conhecimento oficial, e o falseamento de uma ordem e progresso. $\mathrm{O}$ pensamento pedagógico brasileiro começa a ter autonomia apenas com o desenvolvimento das teorias da Escola Nova.

Ao estudar os ensinamentos de Paulo Freire (2002), fica nítida a intenção da imposição da busca de superação da classe menos favorecida, que muitas vezes acabam por reproduzir valores que, por vezes, não se adequam as demandas da sociedade brasileira. Freire deixou precioso legado em sua doutrina, posto que trouxe uma metodologia educacional que permite a emancipação do, por ele chamado, oprimido através, preponderantemente, de sua própria ação (do oprimido). Seu pensamento ressalta a importância do conhecimento da realidade no desenvolvimento da consciência de si e este ao aumento daquele conhecimento. (FREIRE, 2002, p.171).

Neste quadro de reprodução do saber, banalizou o direito educacional, pois a reprodução de uma base curricular não condiz com o dinamismo social vigente. Não permitindo apresentar ao aluno uma análise da realidade. Zanardi, aponta que " $o$ conhecimento escolar, sob pena de ser alienante e estático, não pode desprezar o contexto vivido. Sua função é estabelecer o diálogo entre os saberes científicos e o mundo vivido, pois será na comunidade, onde a escola este inserida, que o conhecimento fará sentido." (ZANARDI, 2013).

Para Paulo Freire (1996), "é importante que seja apresentado ao aluno uma análise de sua realidade fática, entrelaçada as oportunidades de justificá-la" (FREIRE, 1996, p. 12).

É exatamente neste sentido que ensinar não se esgota no "tratamento" do objeto ou do conteúdo, superficialmente feito, mas se alonga à produção das condições em que aprender criticamente é possível. (FREIRE, 1996, p. 15).

Nesta seara, Zanardi, 2013 aponta que:

(...) a construção do conhecimento tem por base, nesta acepção, o diálogo entre sujeitos mediados pelo mundo vivido. Educadores e educandos colocam-se como sujeitos cognoscnete em razão de seu inacabamento e de um mundo que está em processo. A seleção de conteúdos por especialistas distantes desta realidade revelam-se alienadoras dos sujeitos em processo de conhecimento e desprezam o 
mundo vivido e sua possibilidade de transformação. (ZANARDI, 2013).

Nessa perspectiva, vale mencionar a história de Carolina Maria de Jesus, escritora que fora descoberta pelo jornalista Audálio Dantas, o próprio, em prefácio da obra "Quarto de despejo" da referida autora, conta como fora tal descoberta.

Repórter, fui encarregado de escrever uma matéria sobre uma favela que se expandia na beira do Rio Tietê, no bairro do Canindé. Lá, no rebuliço favelado, encontrei a negra Carolina, que logo se colocou como alguém que tinha o que dizer. E tinha! Tanto que, na hora, desisti de escrever a reportagem.

A história da favela que eu buscava estava escrita em uns vinte cadernos encardidos que Carolina guardava em seu barraco. Li, e logo vi; repórter nenhum, escritor nenhum poderia escrever melhor aquela história - a visão de dentro da favela. (JESUS, 1960).

Carolina Maria de origem pobre, catadora de papel, moradora da favela localizada no bairro Canindé, de pouca escolaridade (cursou apenas a primeira e segunda série do ensino fundamental) fez da literatura um meio para expressar suas dores, a pobreza, a fome, chamada por ela como a "amarela", percebe-se o quão valiosa se tornou a literatura na vida da referida escritora. Em sua obra, Carolina Maria afirma a importância do escrever, para ela "uma palavra escrita não pode nunca ser apagada. Por mais que o desenho tenha sido feito a lápis e que seja de boa qualidade a borracha, o papel vai sempre guardar o relevo das letras escritas". (JESUS, 1960).

Nesse prisma, é necessária a observação da representatividade da literatura na vida de Carolina Maria, que mesmo diante de tanta falta material, conseguiu fazer da literatura um caminho para marcar e não deixar ser esquecida a sua história. A literatura como forma de guardiã de histórias contadas por quem viveu na pele as nuance da periferia; a fome marcada pelo lápis possui contornos que jamais poderiam ser expressos com tanta destreza, quanto o foram por ela. Na leitura abaixo é possível verificar tais detalhes, observe-se que o jornalista ao publicar os textos escritos por Carolina respeitou os detalhes próprios de sua obra, inclusive, não alterando sua grafia.

20 DE JULHO Deixei o leito as 4 horas para escrever. Abri a porta e contemplei o céu estrelado. Quando o astro-rei começou despontar eu fui buscar água. Tive sorte! As mulheres não estavam na torneira. Enchi minha lata e zarpei. (...) fui no Arnaldo buscar o leite e o pão. Quando retornava encontrei o senhor Ismael com uma faca de 30 centímetros maisou menos. Disse-me que estava a espera do Binidito e do Miguel para matá-los, que eles lhe expancaram quando ele estava embriagado. Lhe aconselhei a não brigar, 
que o crime não traz vantagens a ninguém, apenas deturpa a vida. Senti o cheiro de álcool, disisti. (JESUS, 1960).

Nesse cenário, vislumbra-se o pensamento freireano que constitui um instrumento indispensável de análise, pois, denuncia a ocultação da realidade, o ensino reprodutor-engessador com o uso da linguagem, que representa uma verdadeira armadilha da ideologia.

Mário Sergio Cortella, em entrevista para o projeto Trilhas do Instituto Natura ("projeto voltado à formação de professores que trabalham com crianças em fase de alfabetização e desejam aproximar a literatura das práticas de sala de aula"), tratou sobre a importância da literatura, para ele a "literatura é aquela que estilhaça o tempo fechado, isto é, o tempo que é recluso no instante, no momento, nos coloca em outros lugares, em outros tempos, outras eras, outras pessoas”. (CORTELLA, 2016).

É justamente nessa linha de pensamento que se visualiza a obra anterior citada "quarto de despejo", na medida em que do mesmo modo que Carolina expressava sua vida no papel, a literatura representou para ela verdadeiras janelas para algo novo, e, para os leitores suas obras significaram uma verdadeira viajem para o conhecimento de uma realidade que não deve ser esquecida, "todo ser humano sempre foi contemporâneo, ninguém na história viveu fora da era contemporânea, cada um na sua, mas, o livro nos aproxima das outras contemporaneidades, nos coloca em outros momentos em que outras pessoas estiveram". (CORTELLA, 2016).

Ao mesmo tempo a literatura nos traz para o agora porque ela também lida
com o nosso cotidiano, então, ela nos aproxima do aqui agora e nos aproxima
da história, permite que a gente fantasie, que a gente medite, muitas vezes
tem a emoção, a meditação, a reflexão; em várias situações a literatura faz
com que nos abstraiamos tudo o que está a nossa volta, ela nos retira do
espaço tempo.
(...) A literatura é alegre, e por isso, séria, seriedade não é sinônimo de
tristeza, o contrário de seriedade não é alegria, o contrário de seriedade é o
descompromisso. E nós temos que ser alegres e sérios, a literatura não nos
deixa indiferente. (CORTELLA, 2016).

Desse modo, objetiva-se no presente estudo, sob uma perspectiva geral, tratar sobre os efeitos da literatura no sistema educacional, como construção da cidadania, bem como sua significação tanto para as crianças que acabaram de iniciar os estudos e está perpassando a fase de desenvolvimento da capacidade cognitiva, quanto para os 
jovens e adultos que resolveram retomar os estudos, de forma a demonstrar que a literatura consiste em um Direito Fundamental na construção do regate do saber em seu espaço dialógico.

No que tange aos objetivos específicos do presente estudo, prima-se por apresentar a importância da Literatura no currículo brasileiro, na busca da aproximação do educando à sua realidade social, como forma de efetivação do direito à educação como Direito Fundamental.

Ademais, busca-se ainda, especificamente, indicar o papel da Literatura no ensino, bem como, sua essencialidade tanto para a alfabetização, quanto para a educação como um todo e, principalmente como modo de combate das próprias mazelas sociais, evidenciando, como a literatura pode influenciar a sociedade, na medida em que, através dela, é possibilitado uma visão maximizada do mundo e poder expressar aquilo que se vive, aquilo que se sente, como fonte primordial de preservação da cultura de cada povo, sociedade, comunidade e nação.

Nesse diapasão, Antônio Cândido (2014), sociólogo e literato, em sua obra "Direitos Humanos e Literatura" faz uma crítica no sentido de que "pensar em direitos humanos tem um pressuposto: reconhecer que aquilo que consideramos indispensável para nós é também indispensável para o próximo", entretanto, as pessoas tendem a afirmar que o semelhante possui o direito a coisas fundamentais para a vida, tais como alimentação, saúde, família, etc, mas, o que se questiona é "será que pensam que o seu semelhante pobre teria direito a ler Dostoievskl ou ouvir os quartetos de Beethoven"? Para o autor, para entender tal fato, é importante refletir sobre os direitos humanos. (CÂNDIDO, p.3, 2014).

O direito à educação parte do reconhecimento de que o saber sistemático é
mais do que uma importante herança cultural. Como parte da herança
cultural, o cidadão torna-se capaz de se apossar de padrões cognitivos e
formativos pelos quais tem maiores possibilidades de participar dos destinos
de sua sociedade e colaborar na sua transformação. Ter o domínio de
conhecimentos sistemáticos é também um patamar sine qua non a fim de
poder alargar o campo e o horizonte destes e de novos conhecimentos.
(CURY, 2002).

Ainda nessa linha, Cândido explica que existem bens que são incompressíveis (alimentação, moradia, vestuário) e outros que são compressíveis (cosméticos, enfeites, roupas extras), entretanto, há uma fronteira entre tais bens, fronteira essa que possui 
certa dificuldade em ser mensurada, ainda quando se pensa no que pode ser considerado como indispensável, logo, tem-se que "o primeiro litro de arroz de uma saca é menos importante do que o último, e sabemos que com base em coisas como esta se elaborou em Economia Política a teoria da "utilidade marginal", tal teoria significa que "o valor de uma coisa depende em grande parte da necessidade relativa que temos dela". (CÂNDIDO, 2014).

O fato é que cada época e cada cultura fixam os critérios de incompressibilidade, que estão ligados à divisão da sociedade em classes, pois inclusive a educação pode ser instrumento para convencer as pessoas de que o que é indispensável para uma camada social não o é para outra. $\mathrm{Na}$ classe média brasileira, os da minha idade ainda lembram o tempo em que se dizia que os empregados não tinham necessidade de sobremesa nem de folga aos domingos, porque, não estando acostumados a isso, não sentiam falta... (CÂNDIDO, 2014).

Aludido autor alerta que é preciso extremo cuidado ao tentar discutir a questão dos critérios incompressíveis, tanto sob a perspectiva individual, quanto social, nesse viés, entende ele que os bens incompressíveis não se limitam àqueles mínimos de uma vida digna, mas, também os que proporcionam e primam pela "integridade espiritual" "são incompressíveis certamente a alimentação, a moradia, o vestuário, a instrução, a saúde, a liberdade individual, o amparo da justiça pública, a resistência à opressão etc.; e também o direito à crença, à opinião, ao lazer e, por que não, à arte e à literatura". (CÂNDIDO, 2014).

\begin{abstract}
Mas a fruição da arte e da literatura estaria mesmo nesta categoria? Como noutros casos, a resposta só pode ser dada se pudermos responder a uma questão prévia, isto é, elas só poderão ser consideradas bens incompressíveis segundo uma organização justa da sociedade se corresponderem a necessidades profundas do ser humano, a necessidade que não podem deixar de ser satisfeitas sob pena de desorganização pessoal ou pelo menos de frustração mutiladora. A nossa questão básica, portanto, é saber se a literatura é uma necessidade deste tipo. Só então estaremos em condições de concluir a respeito. (CÂNDIDO, 2014).
\end{abstract}

Por fim, Cândido (2014) conceitua a literatura como "o sonho acordado das civilizações", explicando, para tanto, que "assim como não é possível haver equilíbrio psíquico sem o sonho durante o sono, talvez não haja equilíbrio social sem a literatura". (CÂNDIDO, p.4, 2014).

Deste modo, ela é fator indispensável de humanização e, sendo assim, confirma o homem na sua humanidade, inclusive porque atua em grande parte no subconsciente e no inconsciente. Neste sentido, ela pode ter importância equivalente à das formas conscientes de inculcamento 
intencional, como a educação familiar, grupal ou escolar. Cada sociedade cria as suas manifestações ficcionais, poéticas e dramáticas de acordo com os seus impulsos, as suas crenças, os seus sentidos, as suas normas, a fim de fortalecer em cada um a presença e atuação deles. (CÂNDIDO, 2014).

Para Freire (1981) a educação é um esforço deliberado para influenciar os tipos e os processos de produção de conhecimentos e identidades em meio a determinados conjuntos de relações. Apresenta preocupações que abrangem a integração, na prática, de certo conteúdo e modelo de organização curricular, estratégias e técnicas didáticas, tempo e espaço para a prática dessas estratégias e técnicas, bem como propósitos e métodos de avaliação. (FREIRE, 1981)

Cabe elucidar aspectos da obra de Paulo Freire em "a importância do ato de ler" tal obra se refere a uma palestra na qual o autor ministrou sobre a "importância do ato de ler em uma comunicação sobre as relações da biblioteca popular com a alfabetização de adultos e em um artigo que expõe a experiência de alfabetização de adultos desenvolvida pelo autor e sua equipe em São Tomé e Príncipe”, nele o educador explica aspectos do processo de sua alfabetização, bem como sobre a importância do ato de ler, conta que fora alfabetizado no chão do quintal de sua casa "fui alfabetizado no chão do quintal de minha casa, à sombra das mangueiras, com palavras do meu mundo e não do mundo maior dos meus pais. O chão foi o meu quadro-negro; gravetos, o meu giz", posteriormente, quando frequentou a escolinha particular de Eunice Vasconcelos já estava alfabetizado "Eunice continuou e aprofundou o trabalho de meus pais. Com ela, a leitura da palavra, da frase, da sentença, jamais significou uma ruptura com a "leitura" do mundo. Com ela, a leitura da palavra foi a leitura da "palavra mundo". (FREIRE, 1981)

Freire faz uma crítica no que diz respeito a forma que os professores tentam transmitir a importância da leitura, criticando o modo exaustivo com que é imposto a leitura ao aluno acaba por limita-lo a verdadeiras "lições de leitura". "Creio que muito de nossa insistência, enquanto professoras e professores, em que os estudantes "leiam", num semestre, um sem-número de capítulos de livros, reside na compreensão errônea que às vezes temos do ato de ler”. (FREIRE, 1981)

Em minha andarilhagem pelo mundo, não foram poucas as vezes em que jovens estudantes me falaram de sua luta às voltas com extensas bibliografias a serem muito mais "devoradas" do que realmente lidas ou estudadas. Verdadeiras "lições de leitura" no sentido mais tradicional desta expressão, a 
que se achavam submetidos em nome de sua formação científica e de que deviam prestar contas através do famoso controle de leitura. Em algumas vezes cheguei mesmo a ler, em relações bibliográficas, indicações em torno de que páginas deste ou daquele capítulo de tal ou qual livro deveriam ser lidas: "Da página 15 à 37". (FREIRE, 1981)

Desse modo, primar pelo extenso tamanho de leitura sem aprofundada compreensão acerca do tema, "mecanicamente memorizados, revela uma visão mágica da palavra escrita. Visão que urge ser superada", (...) "No entanto, um dos documentos filosóficos mais importantes de que dispomos, As teses sobre Feuerbach, de Marx, tem apenas duas páginas e meia...”. (FREIRE, 1981)

Por fim, ressalta-se que no que cerne a alfabetização de adultos, mencionado autor a entende como "um ato político e um ato de conhecimento, por isso mesmo, como um ato criador", na medida em que "enquanto ato de conhecimento e ato criador, o processo da alfabetização tem, no alfabetizando, o seu sujeito". (FREIRE, 1981)

Na verdade, tanto o alfabetizador quanto o alfabetizando, ao pegarem, por
exemplo, um objeto, como laço agora com o que tenho entre os dedos,
sentem o objeto, percebem o objeto sentido e são capazes de expressar
verbalmente o objeto sentido e percebido. Como eu, o analfabeto é capaz de
sentir a caneta, de perceber a caneta e de dizer caneta. Eu, porém, sou capaz
de não apenas sentir a caneta, de perceber a caneta, de dizer caneta, mas
também de escrever caneta e, consequentemente, de ler caneta. A
alfabetização é a criaçãa ou a montagem da expressão escrita da expressão
oral. (FREIRE, 1981)

Desse modo, frisa-se a importância da literatura, portanto, como o próprio ato de ler, no sentido de que estimula a compreensão crítica "interpretação e "re-escrita" do lido". (FREIRE, 1981).

Conclui-se, portanto, o presente escrito reforçando a ideia da inserção da Literatura no currículo escolar como meio de garantia e elevação dos direitos fundamentais a partir do desenvolvimento da consciência do sujeito, na medida em que ele lê, ele pensa, e na medida em que pensa, nasce a crítica, e, por fim, começa a expressar a sua realidade por meio da escrita, e isso é literatura.

A literatura não tem que ser objeto de luxo de determinada classe, muito pelo contrário, está intrinsicamente interligada à educação, de modo que, para que se possa falar de educação efetiva, emancipatória, é preciso falar de literatura. 
Ademais, é importante ressaltar, por fim, a perspectiva da "escola cidadã" levantada por Paulo Freire, no sentido de que, o verdadeiro ensinar não se resume ao mero instrucionismo, mas, vai muito além exercitando a construção da cidadania.

\begin{abstract}
A Escola cidadã é aquela que se assume como centro de direitos, como um centro de deveres. O que a caracteriza é a formação para a cidadania. A Escola Cidadã, então, é escola que viabiliza a cidadania de quem está nela e de quem vem a ela. Ela não pode ser uma escola cidadã em si e para si. Ela é cidadã na medida mesma em que se exercita na construção da cidadania de quem usa o seu espaço. A escola cidadã é uma escola coerente com a liberdade que, brigando para ser ela mesma, lugar para que os educandoseducadores também sejam eles mesmos. E como ninguém pode ser só, a escola cidadã é uma escola de comunidade, de companheirismo. É uma escola que não pode ser jamais licenciosa nem jamais autoritária. É uma escola que vive a experiência tensa da democracia. (FREIRE, 1997).
\end{abstract}

A construção do saber a partir de onde o sujeito vive, de sua condição de vida, da criticidade e é justamente nesse ponto que a Literatura se faz imprescindível. A Literatura exerceria esse papel, viria para concretizar, trazer as vistas esse elemento, essa realidade das pessoas como uma forma de emancipação do sujeito e de trazer a ele um Direito Fundamental a educação.

\title{
5 Conclusão
}

Após os estudos sobre a bibliografia atinente ao tema proposto pelo presente escrito, foi possível concluir que a valorização da Literatura no plano de ensino da educação básica se faz essencial, na medida em que, a prática da leitura crítica proporciona ao educando uma gama de possibilidades de enxergar o mundo e discutir aspectos sociais, históricos, econômicos, entre outros. Aspectos esses que em outra disciplina não seria possível discutir.

Portanto, é por meio da Literatura que o aluno consegue se emancipar de tal forma que uma leitura detalhada de um conto literário possibilitará a troca de experiências com colegas de classe, imergindo e contextualizando a informação, a realidade e, consequentemente produzindo pesquisa e construindo conhecimento.

Ademais, realizada a análise do transcurso da Educação no Brasil, constatou-se que a Lei de Diretrizes e Bases da Educação Nacional - Lei 9.394/96, em que pese o seu objetivo principal de traçar um padrão equitativo de forma a garantir certa coerência no sistema educacional das regiões do país, é válido que se faça o questionamento no que tange as formas de ensino em que se observa um engessamento das áreas de estudo. 
Nesse diapasão, cabe frisar que o objetivo da Literatura não é que ela seja maçante, ou que obrigue o educando a ler determinados números de livros por semana, sem que haja um objetivo, uma discussão, definitivamente, não é isso. Entretanto, o que se espera do papel da literatura na educação básica é que possibilite a desenvoltura do educando, não só em sua capacidade de leitura, como sua argumentação, sua crítica, etc, para que quando chegar à Universidade esteja com uma base e preparado para evoluir em seus estudos.

Desse modo, conclui-se que a Literatura constitui verdadeira fonte emancipatória curricular e traduz a efetivação da educação como um Direito Fundamental.

\section{REFERÊNCIAS}

APPLE, Michael W. Ideologia e currículo. 3. ed. Porto Alegre: Artmed, 2006.

BRASIL. Constituição (1988). Constituição da República Federativa do Brasil. Brasília: Senado, 1988

CÂNDIDO, Antônio. Direitos Humanos e Literatura; disponível em https://bibliaspa.org/wp-content/uploads/2014/09/direitos-humanos-e-literatura-porantonio-candido.pdf. Acesso em 01/03/2018

CURY, Carlos Roberto Jamil. Direito à Educação: Direito à Igualdade, Direito à Diferença. Caderno de Pesquisa. n.116, p.245-262, São Paulo: julho/2002.Disponível em: $\underline{w w w . s c i e l o . b r / s c i e l o}$

CORTELLA, Mário Sérgio. Projeto Trilhas. Entrevista concedida ao projeto Trilhas em 20/10/2016.

DEMO, Pedro. Saber Pensar. - 6. Ed. - Cortez: Instituto Paulo Freire, 2000. - (Guia da escola cidadã).

DURKHEIM, Émile. A educação Moral. São Paulo: Vozes, 2008.

DURKHEIM, Émile. Educação e Sociologia. São Paulo: Melhoramento, 1978. 
MARTINS. As regras do Método sociológico. $3^{\text {a }}$ ed. São Paulo: Martins Fontes,2005

FREIRE, Paulo. Pedagogia da autonomia: saberes necessários à prática educativa. 28. ed. São Paulo: Paz e Terra, 1996.

FREIRE, Paulo. Pedagogia do oprimido. 41. ed. São Paulo: Paz e Terra, 2005.

FREIRE, Paulo. A importância do ato de ler. 21. ed. São Paulo: Paz e Terra, 2005.

HILSDORF, Maria Lucia Spedo.História da Educação Brasileira: Leituras. São Paulo: Pioneira Thomson Learning, 2003

MARCHELLI, Paulo Sérgio. Da LDB 4.024/61 ao debate contemporâneo sobre as bases curriculares nacionais. Revista e-Curriculum. São Paulo, v.12, n3, p.1480-1511 out/dez,2014.

PERRONE-MOISÉS, L. Literatura para todos. Literatura e Sociedade, v. 11, n. 9, p. 16-29, 6 dez. 2006.

QUINTANEIRO, Tania; BARBOSA, Maria Ligia de Oliveira; OLIVEIRA, Marcia Gardênia Monteiro de. Um toque de clássicos: Marx, Durkheim e Weber. 2d., Belo Horizonte: UFMG, 2009

SILVA, Ivanda Maria Martins; Literatura em sala de aula: da teoria literária à prática escolar. Anais do evento PG letras 30 anos, vol.1. p. 514-527, 2003.

SILVA, Tomaz Tadeu da Silva; MOREIRA, Antonio Flávio (orgs). Currículo, Cultura e Sociedade. 8 ed. São Paulo: Cortez, 2005.

WOLKMER, Antônio Carlos. História do Direito no Brasil. 3. ed. Rio de Janeiro: Forense, 2003.

ZANARDI, Teodoro Adriano. Por uma docência jurídica emancipatória: contribuições freireanas ao ensino jurídico(mimeo). 2007 